\title{
Modelling variation in Pinus radiata stem volume and outerwood stress-wave velocity from LiDAR metrics
}

Michael S Watt ${ }^{1 *}$, Thomas Adams ${ }^{2}$, Hamish Marshall ${ }^{3}$, David Pont ${ }^{4}$, John Lee ${ }^{4}$, David Crawley ${ }^{5}$ and Pete Watt ${ }^{6}$

\begin{abstract}
Background: Light Detection and Ranging (LiDAR) is an established technology that has been shown to provide accurate information on individual-tree and stand-level forest structure. Although LiDAR has been widely used to describe stand structural dimensions the utility of this technology to predict spatial variation in wood quality traits is largely unexplored. This study used LiDAR metrics to predict spatial variation in total stem volume (TSV) and outerwood stress-wave velocity $(\boldsymbol{V}$ in an even-aged mature forest (25 yrs) of moderate size (stocked area of 217.8 ha). Outerwood stress-wave velocity is a good predictor of modulus of elasticity which is a key performance criterion for structural timber.
\end{abstract}

Methods: Linear and non-linear models were developed to predict TSV and $V$. Models of TSV were developed from the full dataset that included 163 plots while models of $V$ were developed from a subset of 32 plots in which $V$ had been measured.

Results: The best statistical models that included only LiDAR data, explained $60 \%$ and $37 \%$ of the variation in TSV and $V$, respectively. Addition of measured stand density to both models significantly improved the $R^{2}$ to, respectively, 0.76 and 0.70 for TSV and $V$. The root-mean square error for the final models of TSV and $V$ were, respectively, $64.0 \mathrm{~m}^{3} \mathrm{ha}^{-1}$ and $0.086 \mathrm{~km} \mathrm{~s}^{-1}$.

Conclusion: At the forest level LiDAR metrics were found to be useful for predicting both $V$ and TSV. Further research should examine the link between LiDAR metrics and $V$ across broader ranges of $V$ to confirm these findings.

Keywords: ALS, Aerial laser scanning, Modulus of elasticity, Pinus radiata, Radiata pine

\section{Background}

Light Detection and Ranging (LiDAR) is an established technology that provides a highly accurate measure of distance. Often mounted on an airborne system, the application of LiDAR for aerial laser scanning has been studied in forestry since about 1978 . However, it is only in recent years that the combination of precise airborne navigation, high quality instruments and effective post-processing software has allowed the technology to progress to operational use (Naesset, 1997, 2002). Innovation in laser scanning technology is advancing very rapidly and there are several benchmark papers that describe the technology

\footnotetext{
* Correspondence: michael.watt@scionresearch.com

'Scion, PO Box 29237, Fendalton, Christchurch, New Zealand

Full list of author information is available at the end of the article
}

and review sensor characteristics (Baltsavias, 1999; Hyyppa et al., 2006; Wehr \& Lohr, 1999).

Internationally, LiDAR data have been used within the forest sector to provide estimates of stand height, basal area (Means et al., 1999; Watt, 2005), stem diameter, stem volume (Lim et al., 2003; Lim \& Treitz, 2004; Naesset, 1997; Woods et al., 2008; Woods et al., 2011) canopy properties (Naesset \& Okland, 2002) and species composition (Donoghue et al., 2007). For estimation of tree height and volume the accuracy of LiDAR-derived estimates is reported to be similar to or better than manual field measurement methods (Naesset, 2002; Watt, 2005). LiDAR data are used operationally in, for example, the Nordic countries, to provide estimates of stand dimensions at the compartment level (Eid et al., 2004). However, in the southern 
hemisphere, where Pinus radiata D.Don is the most widely planted conifer species (Lewis \& Ferguson, 1993), little published research has demonstrated the utility of this technology in predicting stand volume at the forest level.

Given the known correlation between stand structural attributes and internal wood properties in a range of conifers (van Leeuwen et al., 2011; Watt \& Zoric, 2010) there is a theoretical basis linking LiDAR metrics to wood properties. Despite this, very little research has demonstrated useful relationships between LiDAR and wood quality traits (Hilker et al., in press; van Leeuwen et al., 2011). In plantation-grown softwoods, such as $P$. radiata, modulus of elasticity $(E)$ is an important wood property that describes resistance of timber to deformation under load. Although $E$ is not an important property for pulp, it is a key performance criterion for structural timber. In standing trees $E$ is most commonly estimated by portable instruments that determine stresswave velocity $(V)$ in outerwood using time of flight methods (Lindström et al., 2002).

Using spatially coincident LiDAR and inventory data obtained from a $P$. radiata forest located within New Zealand, the objective of this research was to construct models between LiDAR metrics and both total stem volume (TSV) and outerwood velocity $(V)$.

\section{Methods}

\section{Data collection}

\section{Stand information}

The data for this study were obtained during late summer 2011 from a 25-year-old forest located in Eastern Bay of Plenty, New Zealand. This forest is located on steep dissected country with an elevation range of approximately 150 to 300 metres above sea level. A standard pre-harvest inventory comprising 163 plots was carried out within the forested area of 217.8 hectares. The circular plots were laid out on a systematic grid. Plot size was varied from 0.06 to 0.09 ha to ensure that approximately 20 trees were included in each plot. The location of the plots was measured using a Trimble Pathfinder Pro XT high grade GPS with data corrected using post processing (accuracy $=0.5 \mathrm{~m}$ ). Within each plot all trees were measured for stem diameter.

Total stem volume, TSV $\left(\mathrm{m}^{3} \mathrm{ha}^{-1}\right)$, was determined from stand basal area, BA $\left(\mathrm{m}^{2} \mathrm{ha}^{-1}\right)$, and mean top height, $H_{\mathrm{t}}$, (m; mean height of the 100 largest diameter trees per ha), using the following nationally applicable equation (Kimberley \& Beets, 2007),

$$
T S V=H_{t} \mathrm{BA}\left(0.942\left(H_{t}-1.4\right)^{-1.161}+0.317\right)
$$

For Equation 1, $H_{\mathrm{t}}$ was determined directly from LiDAR metrics using the following unbiased and accurate $\left(R^{2}=0.95\right.$; root mean square error $\left.=1.91 \mathrm{~m}\right)$ nationally applicable equation, derived from an extensive set of LiDAR metrics and field measurements (Watt \& Watt, in press),

$$
H_{t}=2.442+0.992 H_{95}
$$

where $H_{95}(\mathrm{~m})$ is the $95^{\text {th }}$ percentile of the LiDAR height distribution. Stem slenderness was defined from the plot data as $H_{\mathrm{t}} /$ mean stem diameter. For each plot stand density was determined as the actual number of trees $\mathrm{ha}^{-1}$.

\section{Outerwood velocity}

Outerwood stress-wave velocity ( $V$ ) was measured in 32 of the inventory plots. Plots were selected to cover the range in stem slenderness and stand density present throughout the forest as both factors are significant determinants of $V$ (Lasserre et al., 2008; Waghorn et al., 2007; Watt \& Zoric, 2010). Where possible, measurements were taken from at least 20 trees within the plot.

Velocity measurements, centred about breast height $(1.4 \mathrm{~m})$, were taken using the ST300 tool (Fibre-gen, New Zealand). Using paths that avoided any large branch stubs or obvious malformations, two measurements were taken either side of the stem (ca. 180 apart) and averaged. The path length between transmitter probe and receiver probe sensors was approximately $1 \mathrm{~m}$.

\section{LiDAR dataset}

Light detection and ranging data and aerial imagery were collected by New Zealand Aerial Mapping, who flew over the site between 24 May and 1 June 2011. Data were captured using New Zealand Aerial Mapping's Optech ALTM 3100EA LiDAR system (05SEN178) and Trimble AIC medium-format digital camera. The LiDAR data were collected at a minimum of 2 points $\mathrm{m}^{-2}$ on open ground. The raw LiDAR data was processed by the supplier into LAS format and georeferenced into the New Zealand Transverse Mercator (NZTM) coordinate system. Classified ground returns were used to construct a Digital Terrain Model (DTM) by connecting them into a Triangulated Irregular Network (TIN) followed by linear interpolation onto a regular grid. All returns within $0.5 \mathrm{~m}$ of the ground were eliminated to remove the effects of understorey vegetation. LiDAR metrics used in the modelling were extracted above the circular plots using corrected GPS locations with the ClipData and CloudMetrics tools from the Fusion software (McGaughey \& Carson, 2003).

\section{Predictive variables used for the modelling}

The LiDAR metrics used in the modelling consisted of height percentiles $\left(H_{5}-H_{95}\right)$, the mean $\left(H_{\text {mean }}\right)$ and 
Table 1 Mean and range for variables used in analyses

\begin{tabular}{|c|c|c|c|c|c|c|c|c|}
\hline & \multicolumn{4}{|c|}{ Stem volume } & \multicolumn{4}{|c|}{ Outerwood stress-wave velocity } \\
\hline & Mean & Range & $R$ & $P$-value & Mean & Range & $R$ & $P$-value \\
\hline \multicolumn{9}{|l|}{ Stand dimensions } \\
\hline Stand density (stems ha ${ }^{-1}$ ) & 248 & $114-433$ & 0.66 & $<0.0001$ & 242 & $114-433$ & 0.50 & 0.0032 \\
\hline Slenderness $\left(\mathrm{m} \mathrm{m}^{-1}\right)$ & 72.1 & 48.8-99.4 & 0.04 & 0.58 & 74.5 & 48.8-99.4 & 0.64 & $<0.0001$ \\
\hline Mean top height (m) & 36.3 & $27.1-41.4$ & 0.30 & $<0.0001$ & 36.9 & $28.1-41.4$ & 0.50 & 0.0033 \\
\hline Diameter (cm) & 50.8 & $39.2-67.1$ & 0.16 & 0.036 & 50.7 & $39.2-64.0$ & -0.68 & $<0.0001$ \\
\hline Basal area $\left(\mathrm{m}^{2} \mathrm{ha}^{-1}\right)$ & 49.3 & $23.7-75.8$ & 0.94 & $<0.0001$ & 47.1 & $23.7-70.0$ & -0.03 & 0.88 \\
\hline \multicolumn{9}{|l|}{ Topographical variables } \\
\hline Slope $\left({ }^{\circ}\right)$ & 28.9 & $9.0-45.0$ & 0.03 & 0.75 & 29.6 & $14.0-45.0$ & 0.37 & 0.036 \\
\hline Aspect $\left({ }^{\circ}\right)$ & 175 & $0-356$ & 0.0007 & 0.99 & 173 & $30-356$ & -0.22 & 0.22 \\
\hline \multicolumn{9}{|l|}{ Selected LiDAR metrics } \\
\hline$H_{95}(\mathrm{~m})$ & 34.1 & 24.9-39.3 & 0.30 & $<0.0001$ & 34.7 & $25.8-39.3$ & 0.50 & 0.0033 \\
\hline$H_{30}(\mathrm{~m})$ & 16.9 & $5.7-25.5$ & 0.77 & $<0.0001$ & 16.7 & $8.3-24.1$ & 0.002 & 0.99 \\
\hline$P C_{\text {veg }}(\%)$ & 98.8 & $80.3-100.0$ & 0.14 & 0.086 & 98.6 & 89.8-100.0 & -0.20 & 0.27 \\
\hline$H_{s d}(m)$ & 9.9 & $6.9-12.9$ & 0.04 & 0.65 & 10.1 & $6.9-12.9$ & 0.55 & 0.0010 \\
\hline
\end{tabular}

Also shown are summary statistics describing the strength and significance of the relationship of each variable with stem volume and outerwood stress-wave velocity. Shown are the correlation coefficient $(R)$ and $P$-value for simple linear correlations. Abbreviations for LiDAR metrics are as follows: $H_{95}$ and $H_{30}-95^{\text {th }}$ and $30^{\text {th }}$ LiDAR height percentiles, $P C_{\text {veg }}$-percentage of first returns from the vegetation (above the cutoff of $0.5 \mathrm{~m}$ ), $H_{\mathrm{sd}}-\mathrm{standard}$ deviation of LiDAR height.

maximum height $\left(H_{\max }\right)$, several metrics describing the LiDAR height distribution through the canopy (skewness, coefficient of variation, standard deviation $\left(H_{\mathrm{sd}}\right)$, kurtosis) and measures of canopy density such as the percentage of returns reaching within $0.5 \mathrm{~m}$ of the ground $\left(P C_{\text {zero }}\right)$ and the percentage of first returns above $0.5 \mathrm{~m}\left(P C_{\mathrm{veg}}\right)$.

Variables describing site topography and stand structure were also used in the modelling. These variables included aspect, slope, stand density, stem slenderness, basal area, mean diameter and $H_{\mathrm{t}}$. Aspect was determined using a digital terrain model while slope was measured in the field.

\section{Analysis}

Linear and non-linear models to predict TSV and $V$ were developed using PROC GLM and PROC NLIN in SAS (SAS-Institute-Inc, 2000). Variables were introduced sequentially into each model starting with the variable that exhibited the strongest correlation, until further additions were either not significant or did not markedly improve model precision $\left(R^{2}\right.$ gains of $\left.<5 \%\right)$. Variable selection was undertaken manually, one variable at a time, and plots of residuals were examined prior to variable addition to ensure that the variable was included in the model using the least biased functional form.

Model precision was determined using the coefficient of determination $\left(R^{2}\right)$ and the root mean square error (RMSE). Model bias was determined through plotting predicted against measured values. Residual values (measured predicted values) were plotted against predicted values, all independent variables in the model and key variables not included in the models. The contribution and functional form of each variable in both of the final models were examined through partial response functions. These partial response functions were generated across the range of each variable whilst holding other variables at mean values in the dataset.

\section{Results}

\section{Data ranges}

Mean values for TSV and $V$ were, respectively, $594.5 \mathrm{~m}^{3} \mathrm{ha}^{-1}$ and $4.31 \mathrm{~km} \mathrm{~s}^{-1}$, with respective ranges of 296-908 $\mathrm{m}^{3} \mathrm{ha}^{-1}$ and $3.79-4.52 \mathrm{~km} \mathrm{~s}^{-1}$. Ranges for stand dimensions, LiDAR

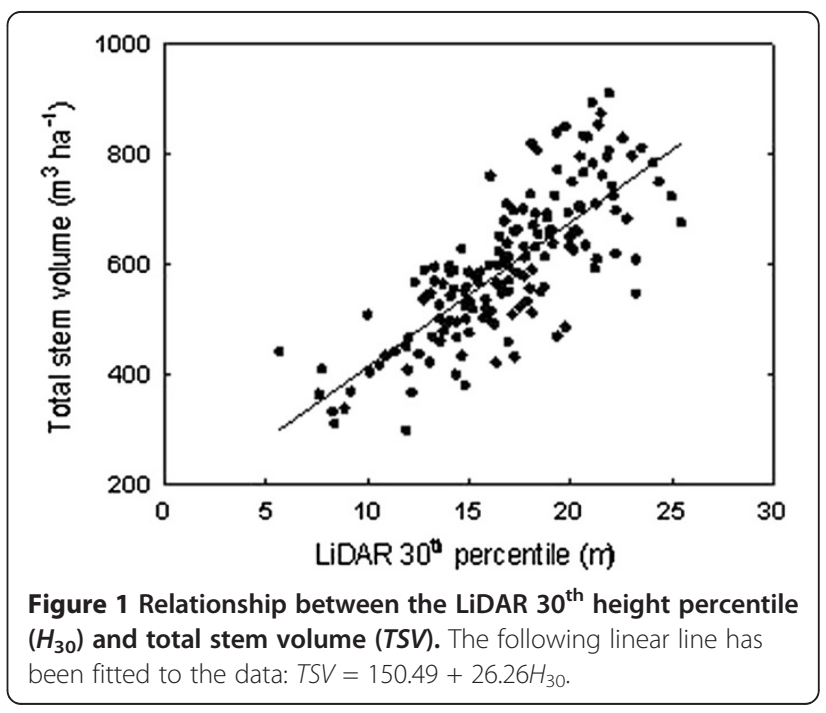




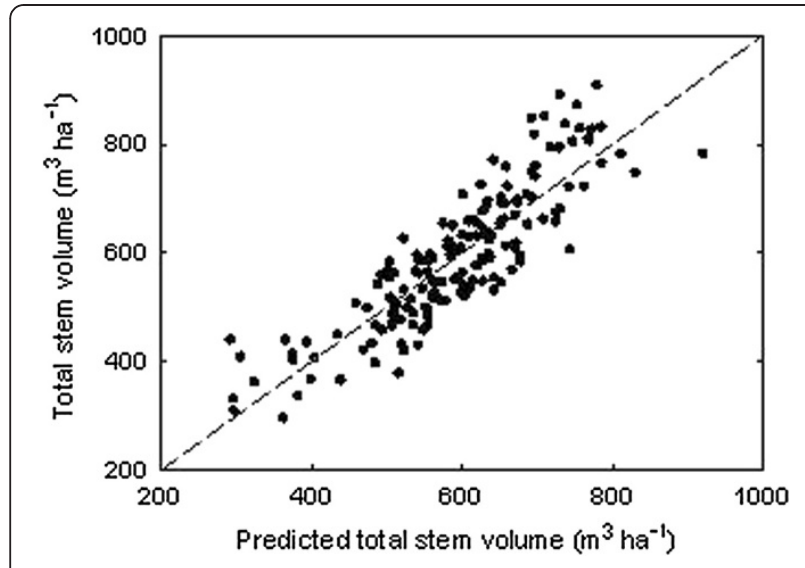

Figure 2 Relationship between total stem volume and values predicted by Equation (4). For reference the 1:1 line is shown as a dashed line.

metrics and topographical variables were similar between the full dataset and that used to determine $V$ (Table 1). In the full dataset, stem slenderness and stem diameter ranged two-fold while basal area varied three-fold. Mean top height, as estimated by LiDAR, ranged from 27.1-41.4 $\mathrm{m}$. Slope

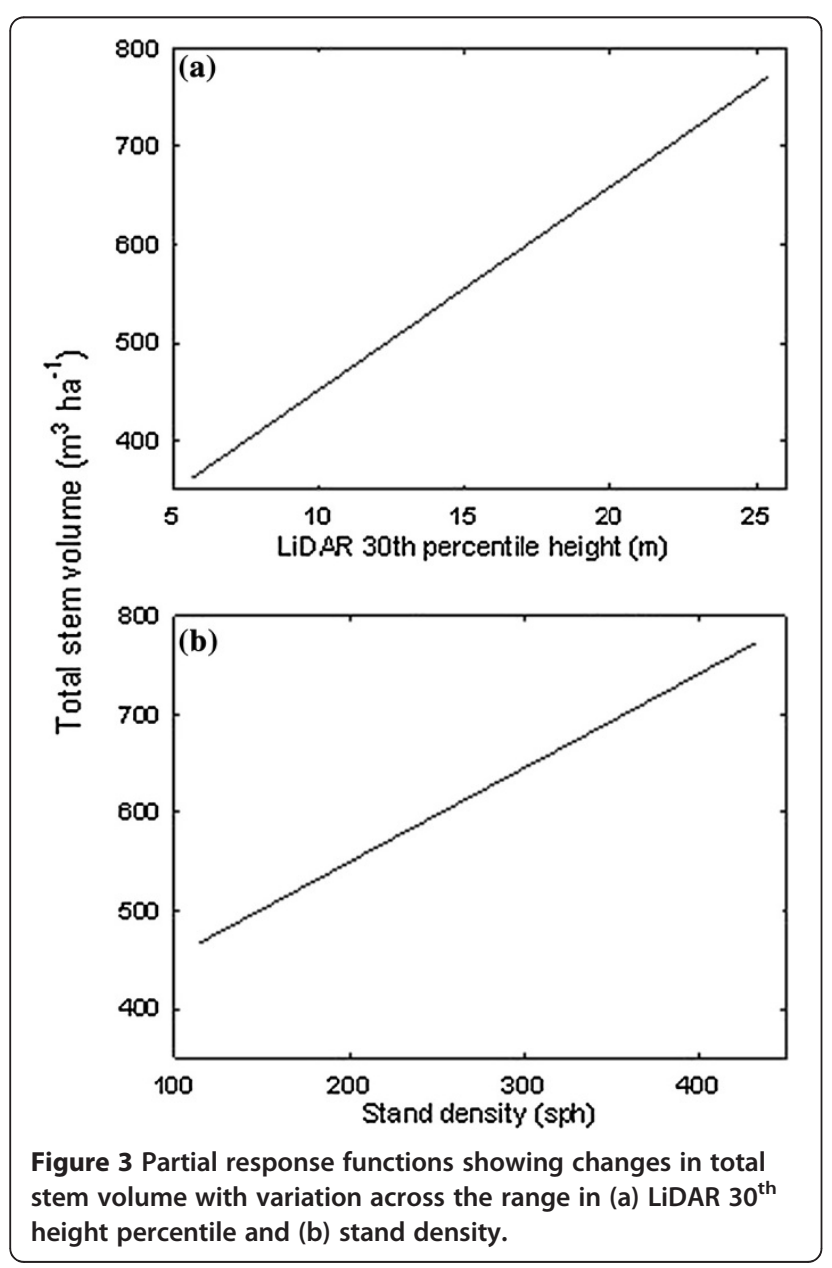

varied five-fold and almost the complete range of aspects were included in the dataset. There was a relatively wide range in LiDAR metrics with the $30^{\text {th }}$ LiDAR height percentile $\left(H_{30}\right)$ showing greatest variation from 5.7 to $25.5 \mathrm{~m}$.

\section{Bivariate correlations}

Both TSV and $V$ were significantly correlated to stand density, mean top height and stem diameter (Table 1). There was also a moderate correlation between $V$ and slenderness that had an $R^{2}$ of 0.56 when a second order polynomial function, with curvilinearity, was used to characterise the relationship. With the exception of the significant relationship between slope and $V$, none of the topographical variables were significantly related to either $V$ or TSV (at $P=0.05$ ). Of the LiDAR metrics considered, TSV was most strongly related to $H_{30}$, while the standard deviation of height $\left(H_{\mathrm{sd}}\right)$ was the strongest predictor of $V$ (Table 1).

\section{Total stem volume}

The $30^{\text {th }}$ LiDAR height percentile $\left(H_{30}\right)$ accounted for $60 \%$ of the variation in TSV (Figure 1), with RMSE of $82.3 \mathrm{~m}^{3} \mathrm{ha}^{-1}$, using the following highly significant $(P<0.0001)$ linear equation,

$$
T S V=150.49+26.26 H_{30}
$$

The best model of TSV included only $H_{30}$ and stand density $(S)$ obtained from the ground plots, in the following equation,

$$
T S V=7.57+20.68 H_{30}+0.96 S
$$

The overall model was highly significant $(P<0.0001)$ as were the two variables included in the model $(P<0.0001)$. The model accounted for $76 \%$ of the variation in TSV and had a RMSE of $64.0 \mathrm{~m}^{3} \mathrm{ha}^{-1}$. A plot of predicted against

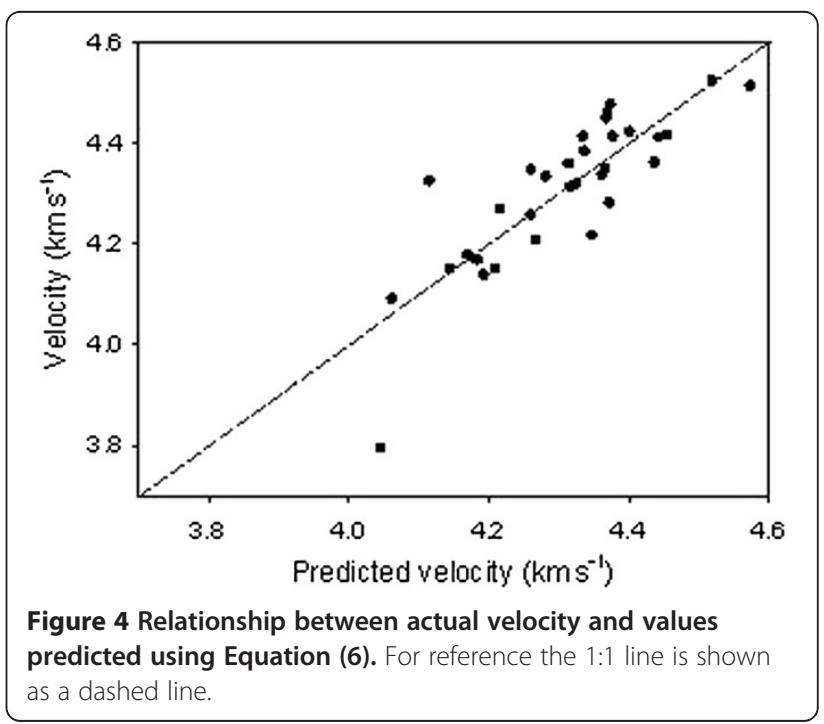


actual TSV showed the model to be relatively unbiased (Figure 2). Partial response functions showing the change in $T S V$ with changes in both variables show the model to be more sensitive to $H_{30}$ than $S$ (Figure 3). Model residuals of $T S V$ were normally distributed (Shapiro-Wilk $P>0.05$ ) and exhibited little correlation with either the variables in the model or those that were excluded from the model (data not shown).

\section{Outerwood velocity}

The best predictive model of $V$ (using only LiDAR variables as possible components) included the standard deviation in LiDAR heights $\left(H_{\mathrm{sd}}\right)$ and the percentage of first returns from the vegetation $\left(P C_{\mathrm{veg}}\right)$. The model had an $R^{2}$ of 0.37 , RMSE of $0.12 \mathrm{~km} \mathrm{~s}^{-1}$, and was described by,

$$
V=5.41+0.0732 H_{\mathrm{sd}}-0.0187 P C_{\mathrm{veg}}
$$

The overall model was significant $(P=0.0013)$ as was $H_{\text {sd }}(P<0.0001)$. Although $P C_{\text {veg }}$ was marginally insignificant $(P=0.11)$, this variable was retained as it was a useful predictor in the more complex model outlined below. With the exception of one outlier, a plot of model predictions against actual velocity showed little apparent bias (data not shown).

Using all available variables the best predictive model of $V$ included $H_{\mathrm{sd}}, P C_{\mathrm{veg}}$ and stand density $(S)$ in the following formulation,

$$
\begin{aligned}
V= & 7.08+0.0690 H_{\mathrm{sd}}-0.0423 P C_{\mathrm{veg}} \\
& +0.893(1-\exp (-0.00691 S))
\end{aligned}
$$

The overall model was significant as were all variables $(P<0.05)$. The model accounted for $70 \%$ of the variance in $V$, with RMSE of $0.086 \mathrm{~km} \mathrm{~s}^{-1}$. A plot of predictions against actual velocity was relatively unbiased (Figure 4), although there was one outlier with a low $V$ (Figure 4). Removal of the outlier had little effect on the precision of the model with the $R^{2}$ reduced from 0.70 to 0.69 . Residuals from the final model were normally distributed (Shapiro-Wilk $P>0.05$ ) and showed little pattern when plotted against any of the variables in the model or any of the key variables not included within the model (e.g. slope, aspect).

Partial response functions show linear relationships between $V$ and all variables apart from stand density. For stand density, there was an exponential increase in $V$ that approached a threshold at stand densities exceeding 400 stems ha $^{-1}$ (Figure 5).

\section{Discussion}

This study showed LiDAR metrics to be significantly related to both TSV and $V$. Inclusion of stand density into these two regression models greatly improved the
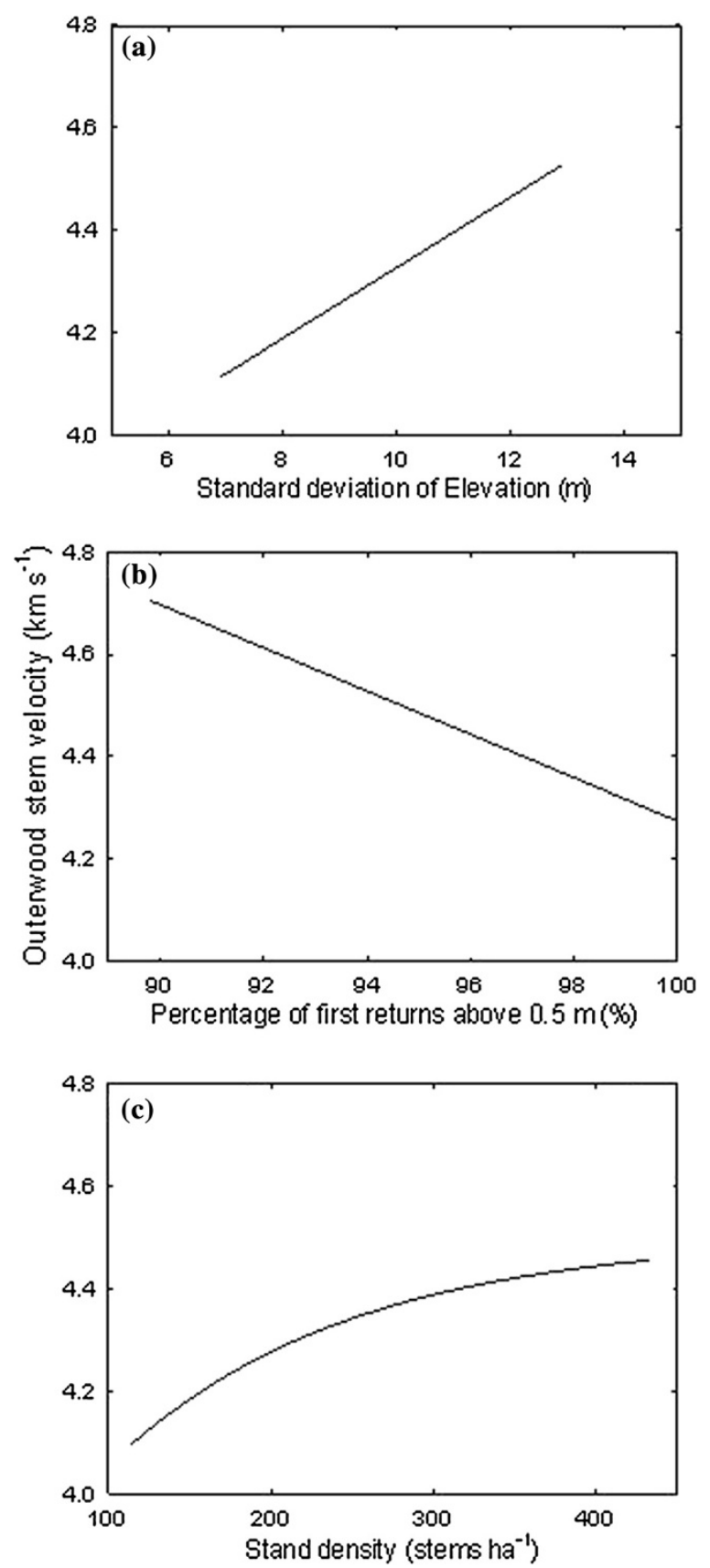

Figure 5 Partial response functions showing changes in outerwood stem velocity with variation across the range in (a) standard deviation of elevation, (b) percentage of first returns from the vegetation (above $0.5 \mathrm{~m}$ ) and (c) stand density.

predictive power of these relationships, highlighting how knowledge of stand density can be useful at both the intra and inter stand level. Little research has demonstrated a link between LiDAR metrics and wood quality attributes such as $V$ and further studies should be undertaken to explore the generality of this relationship. 
The variables included in the final model of $V$ are likely to be significant predictors of $V$ as they are significantly related to stem slenderness. As found here, stem slenderness has previously been identified as one of the key drivers of $V$ and modulus of elasticity (Watt et al., 2009; Watt \& Zoric, 2010). Both standard deviation of height $\left(H_{\mathrm{sd}}\right)$ and stand density exhibited highly significant $(P<0.001)$ positive relationships with stem slenderness.

There is a biological basis for the relationships between stem slenderness and both $H_{\text {sd }}$ and stand density. $H_{\text {sd }}$ describes variation in LiDAR heights in the canopy and provides a measure of stand porosity (the ratio or percentage of pore space to the space occupied by tree stems, branches, twigs and leaves). It has a strong correlation with upper LiDAR metrics, reflecting increases in stem slenderness as the stand height increases. The positive relationship between stand density and slenderness, found here, has been well described previously for light demanding conifers such as $P$. radiata (Watt \& Kirschbaum, in press) and results from greater height extension than diameter growth in response to increasing competition for light. Although the percentage of first returns from vegetation $\left(P C_{\mathrm{veg}}\right)$ was not significantly related to slenderness $(P=0.28)$ this variable was retained in the final model of $V$ as there was a clear relationship between $P C_{\mathrm{veg}}$ and $V$.

Predictive power of the best TSV model shown here was within the range cited by previous localised studies where coefficient of determinations varied from 0.46 (Naesset, 1997) to 0.97 (Means et al., 2000). The relatively high coefficient of determination found here partially reflects a wide range in the dependant variable (TSV) that tends to inflate the percentage of variance explained. As RMSE is not subject to the same limitation, this statistic provides a more conservative estimate of precision. When compared to previous research the RMSE for the best model of $64.0 \mathrm{~m}^{3} \mathrm{ha}^{-1}$ found here is within the mid-range of previous values that include $28 \mathrm{~m}^{3} \mathrm{ha}^{-1}$ (Naesset, 1997, 2002; van Aart et al., 2006), 18.3 - $31.9 \mathrm{~m}^{3} \mathrm{ha}^{-1}$ (Holmgren \& Jonsson, 2004), 38.0 - $56.7 \mathrm{~m}^{3} \mathrm{ha}^{-1}$ (Naesset, 2002), 26.1 - $82.8 \mathrm{~m}^{3} \mathrm{ha}^{-1}$ (van Aart et al., 2006) and $73 \mathrm{~m}^{3} \mathrm{ha}^{-1}$ (Means et al., 2000).

The variables included in the final models were consistent with previous research and have sound mechanistic basis. Logically, LiDAR models describing TSV should combine stem height with variables that provide a measure of stand density and stem diameter. The stem height variable used, $H_{30}$, was appropriate as is affected by the point cloud of almost all trees of significant size, as opposed to top-end height percentiles (e.g. $H_{95}$ ) that are only altered by the point clouds of the highest trees. Inclusion of stand density determined from plot measurements was found to be superior to the use of LiDAR metrics that approximate this quantity (e.g. $P C_{\mathrm{veg}}$ ).

Stand density could be included as a driving variable at a range of resolutions. At a coarse level, stand density for the compartment could be used as input to the model. Alternatively tree counting software such as TiMBRs could be used to identify tree locations (Culvenor et al., 1998; Culvenor, 2002) which could then be used to estimate local stand density above each ground plot and over the whole stand using an appropriate grid size.

\section{Conclusions}

In conclusion, LiDAR metrics were found to be of considerable use for predicting $V$ and TSV at the forest level. The most precise models of $V$ and TSV included stand density as a predictive variable. Little research has demonstrated a link between LiDAR metrics and wood quality metrics such as $V$. Given that $V$ is an important determinant of structural grade timber value further research into the link between LiDAR metrics and $V$ would be warranted.

\section{Competing interests}

The authors declare that they have no competing interests.

\section{Authors' contributions}

MSW was the primary author and undertook the analysis. TA undertook the data extraction. HM organised the fieldwork. DP was involved with the planning of the study, data extraction and assisted with interpretation of results. JL was the senior technician involved in data collection. DC was involved in all aspects of the planning and execution of the study and was the key industry contact. PW provided input around planning, writing and interpretation of results. All authors read and approved the final manuscript.

\section{Acknowledgements}

This project was funded within the Intensive Forest Systems project of Future Forests Research Ltd. We thank PF Olsen for provision of the LiDAR dataset.

\section{Author details}

${ }^{1}$ Scion, PO Box 29237, Fendalton, Christchurch, New Zealand. ${ }^{2}$ MetService, 30 Salamanca Road, Kelburn, Wellington 6021, New Zealand. ${ }^{3}$ Interpine Forestry Ltd., 99 Sala Street, Rotorua, New Zealand. ${ }^{4}$ Scion, Private Bag 3020, Rotorua, New Zealand. ${ }^{5}$ PF Olsen, PO Box 1127, Rotorua, New Zealand. ${ }^{6}$ Indufor AsiaPacific Ltd, PO Box 105039, Auckland, New Zealand.

Received: 15 January 2013 Accepted: 16 January 2013

Published: 13 February 2013

\section{References}

Baltsavias, EP (1999). Airborne laser scanning: basic relations and formulas. Isprs Journal of Photogrammetry and Remote Sensing, 54(2-3), 199-214.

Culvenor, DS, Coops, NC, Preston, R, \& Tolhurst, K (1998). A spatial clustering approach to automated crown delineation. In D. A. Hill \& D. G. Leckie (Eds.) Automated interpretation of high spatial resolution digital imagery for forestry (pp. 67-80). British Columbia: Victoria

Culvenor, DS (2002). TIDA: An algorithm for the delineation of tree crowns in high spatial resolution remotely sensed imagery. Computer \& Geosciences, 28, 33-44.

Donoghue, DNM, Watt, PJ, Cox, NJ, \& Wilson, J (2007). Remote sensing of species mixtures in conifer plantations using LiDAR height and intensity data. Remote Sensing Environment, 110, 509-522.

Eid, T, Gobakken, T, \& Naesset, E (2004). Comparing stand inventories for large areas based on photo-interpretation and laser scanning by means of costplus-loss analyses. Scandinavian Journal of Forest Research, 19(6), 512-523.

Hilker, T, Frazer, GW, Coops, NC, WUlder, GJ, Newnham, JD, Stewart, M, van Leeuwen, M, \& Culvernor, DS (in press). Prediction of Wood Fiber Attributes from LiDAR-Derived Forest Canopy Indicators. Forest Science. 
Holmgren, G, \& Jonsson, T (2004). Large scale airborne laser scanning of forest resources in Sweden. International Archives of photogrammetry, remote sensing and spatial information sciences XXXV1 - 8/W2.

Hyyppa, J, Hyyppa, H, Leckie, D, Gougeon, F, Yu, X, \& Maltamo, M (2006). Review of methods of small-footprint airborne laser scanning for extracting forest inventory data in boreal forests. International Journal Of Remote Sensing, 29, 1339-1366

Kimberley, MO, \& Beets, PN (2007). National volume function for estimating total stem volume of Pinus radiata stands in New Zealand. New Zealand Journal of Forestry Science, 37, 355-371.

Lasserre, JP, Mason, EG, \& Watt, MS (2008). Influence of the main and interactive effects of site, stand stocking and clone on Pinus radiata D. Don corewood modulus of elasticity. Forest Ecology and Management, 255(8-9), 3455-3459.

Lewis, NB, \& Ferguson, IS (1993). Management of radiata pine. Melbourne: Inkata Press.

Lim, K, Treitz, P, Baldwin, K, Morrison, I, \& Green, J (2003). LiDAR remote sensing of biophysical properties of tolerant northern hardwood forests. Canadian Journal of Remote Sensing, 29, 658-678.

Lim, K, \& Treitz, P (2004). Estimation of aboveground forest biomass from airborne discrete return laser scanner data using canopy based quantile estimators. Scandinavian Journal of Forest Research, 19, 558-570.

Lindström, H, Harris, P, \& Nakada, R (2002). Methods for measuring stiffness of young trees. Holz als Roh und Werkstoff, 60, 165-174.

McGaughey, RJ, \& Carson, WW (2003). Fusing LIDAR data, photographs, and other data using 2D and 3D visualization techniques. In: Proceedings of Terrain Data: Applications and Visualization - Making the Connection; October 28-30, 2003 (pp. 16-24). Charleston, South Carolina: Bethesda, MD: American Society for Photogrammetry and Remote Sensing.

Means, JE, Acker, SA, Harding, DJ, Blair, JB, Lefsky, MA, Cohen, WB, Harmon, ME, McKee, WA, et al. (1999). Use of large-footprint scanning airborne LiDAR to estimate forest stand characteristics in the Western Cascades of Oregon. Remote Sensing of Environment, 67(3), 298-308.

Means, JE, Acker, SA, Fitt, BJ, Renslow, M, Emerson, L, \& Hendrix, CJ (2000). Predicting forest stand characteristics with airborne scanning LiDAR. Photogrammetric Engineering and Remote Sensing, 66(11), 1367-1371.

Naesset, E (1997). Estimating timber volume of forest stands using airborne laser scanner data. Remote Sensing of Environment, 61(2), 246-253.

Naesset, E (2002). Predicting forest stand characteristics with airborne scanning laser using a practical two-stage procedure and field data. Remote Sensing of Environment, 80(1), 88-99.

Naesset, E, \& Okland, T (2002). Estimating tree height and tree crown properties using airborne scanning laser in a boreal nature reserve. Remote Sensing of Environment, 79(1), 105-115.

SAS-Institute-Inc. (2000). SAS/STAT User's Guide: Version 8. Volumes 1,2 and 3 (p. 3884). Cary, North Carolina: SAS Institute Inc.

van Aart, JAN, Wynne, RH, \& Oderwald, R (2006). Forest volume and biomass estimation using small-footprint Lidar-distributional parameters on a persegment basis. Forest Science, 52, 636-649.

van Leeuwen, M, Hilker, T, Coops, NC, Frazer, G, Wulder, MA, Newnham, GJ, Culvenor, DS, et al. (2011). Assessment of standing wood and fiber quality using ground and airborne laser scanning: A review. Forest Ecology and Management, 261(9), 1467-1478.

Waghorn, MJ, Watt, MS, \& Mason, EG (2007). Influence of tree morphology, genetics, and initial stand density on outerwood modulus of elasticity of 17year-old Pinus radiata. Forest Ecology and Management, 244, 86-92.

Watt, MS, Clinton, PC, Parfitt, RL, Ross, C, \& Coker, G (2009). Modelling the influence of site and weed competition on juvenile modulus of elasticity in Pinus radiata across broad environmental gradients. Forest Ecology and Management, 258(7), 1479-1488.

Watt, PJ, Watt, MS (in press). Development of a national model of tree volume from LiDAR metrics for New Zealand. International Journal Of Remote Sensing.

Watt, MS, \& Zoric, B (2010). Development of a model describing modulus of elasticity across environmental and stand density gradients in plantationgrown Pinus radiata within New Zealand. Canadian Journal of Forest Research-Revue Canadienne De Recherche Forestiere, 40(8), 1558-1566.

Watt, MS, \& Kirschbaum, MUF (2011). Moving beyond simple linear allometric relationships between tree height and diameter. Ecological Modelling, 222, 3910-3916.

Watt, PJ (2005). An evaluation of LiDAR and optical satellite data for the measurement of structural attributes in British upland conifer plantation forestry. Doctoral thesis. England: Department of Geography, University of Durham.
Wehr, A, \& Lohr, U (1999). Airborne laser scanning - an introduction and overview. Isprs Journal Of Photogrammetry And Remote Sensing, $54(2-3), 68-82$.

Woods, M, Lim, K, \& Treitz, P (2008). Predicting forest stand variables from LiDAR data in the Great Lakes - St. Lawrence forest of Ontario. Forestry Chronicle, 84(6), 827-839.

Woods, M, Pitt, D, Penner, M, Lim, K, Nesbitt, D, Etheridge, D, Treitz, P, et al. (2011). Operational implementation of a LiDAR inventory in Boreal Ontario. Forestry Chronicle, 87(4), 512-528.

doi:10.1186/1179-5395-43-1

Cite this article as: Watt et al:: Modelling variation in Pinus radiata stem volume and outerwood stress-wave velocity from LiDAR metrics. New Zealand Journal of Forestry Science 2013 43:1.

\section{Submit your manuscript to a SpringerOpen ${ }^{\odot}$ journal and benefit from:}

- Convenient online submission

$\checkmark$ Rigorous peer review

- Immediate publication on acceptance

- Open access: articles freely available online

- High visibility within the field

- Retaining the copyright to your article

Submit your next manuscript at $\boldsymbol{~ s p r i n g e r o p e n . c o m ~}$ 